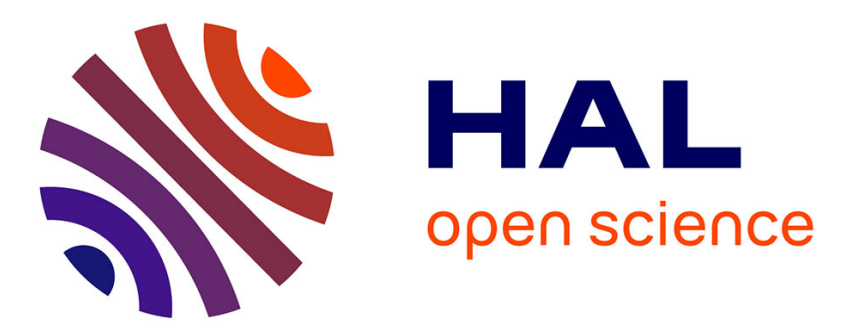

\title{
From Practices to Values: Farmers' Relationship with Soil Biodiversity in Europe
}

Morgane E.T. Hervé, Michel Renault, Elke Plaas, Rebekka Schuette, Martin Potthoff, Daniel Cluzeau, Annegret Nicolai

\section{- To cite this version:}

Morgane E.T. Hervé, Michel Renault, Elke Plaas, Rebekka Schuette, Martin Potthoff, et al.. From Practices to Values: Farmers' Relationship with Soil Biodiversity in Europe. Sociologia Ruralis, 2020, 60 (3), pp.596-620. 10.1111/soru.12303 . hal-02877792

\section{HAL Id: hal-02877792 \\ https://hal.science/hal-02877792}

Submitted on 23 Jun 2020

HAL is a multi-disciplinary open access archive for the deposit and dissemination of scientific research documents, whether they are published or not. The documents may come from teaching and research institutions in France or abroad, or from public or private research centers.
L'archive ouverte pluridisciplinaire HAL, est destinée au dépôt et à la diffusion de documents scientifiques de niveau recherche, publiés ou non, émanant des établissements d'enseignement et de recherche français ou étrangers, des laboratoires publics ou privés. 


\section{From practices to values: farmers' relationship with soil biodiversity in Europe}

Short running title: Farmers' practices and soil biodiversity values

Morgane E.T. Hervé (1)(2)(3); Corresponding author

PhD student

(1) Univ Rennes, ECOBIO - UMR 6553, Biological Station Paimpont, F-35000 Rennes, France;

(2) Univ Rennes; CREM - UMR 6211, F-35000 Rennes, France;

(3) University of Goettingen; Center of Biodiversity and Sustainable Land Use, D-37077, Germany; morgane.herve@univ-rennes1.fr

$+33.2 .99 .61 .81 .70$

ORCID: 0000-0003-0365-8521

Michel Renault (2);

Lecturer

(2) Univ Rennes; CREM - UMR 6211, F-35000 Rennes, France;

Elke Plaas (4);

Researcher

(4) University of Goettingen; Department of Agricultural Economics and Rural Development, D-37073 Germany;

Rebekka Schuette (3)(4);

Post-doctoral researcher

(3) University of Goettingen; Center of Biodiversity and Sustainable Land Use, D-37077 Germany;

(4) University of Goettingen; Department of Agricultural Economics and Rural Development D-37073, Germany;

Martin Potthoff (3);

Lecturer; scientific coordinator

(3) University of Goettingen; Center of Biodiversity and Sustainable Land Use, D-37077 Germany; 
Daniel Cluzeau (1);

Lecturer

(1) Univ Rennes, ECOBIO - UMR 6553, Biological Station Paimpont, F-35000 Rennes, France;

Annegret Nicolai (1)(5)

Researcher

(1) Univ Rennes, ECOBIO - UMR 6553, Biological Station Paimpont, F-35000 Rennes, France;

(5) Agrocampus Ouest, SAS - UMR 1069, F-35000 Rennes, France

ORCID: 0000-0001-7099-5603 


\section{ACKNOWLEDGEMENT}

The authors thank a lot Tania Runge (Thünen Institute) for her great expertise in preparing, organizing and implementing the Focus Groups, Holger Bergmann (Georg-August-Universität Göttingen) for his precise and relevant comments and advice on the manuscript, and Alexandra Langlais (University of Rennes) for the constructive discussions on the European soil and agriculture policies. For the huge help provided to organize and to moderate the Focus Groups, the authors thank Gema Guzmán Díaz and Blanca B. Landa (Spanish National Research Council-Institute for Sustainable Agriculture) in Spain, Jan Bengtsson, Astrid Taylor and Kaisa Torppa (Swedish University of Agricultural Sciences) in Sweden and Mignon Sandor and Valentina Sandor (Universitatea de Ştiinţe Agricole şi Medicină Veterinară din Cluj-Napoca) in Romania. Thanks to Marylou Giacometti for her language advice. The authors especially acknowledge the farmers from the five countries who accepted to participate to the Focus Groups: this work would not have been possible without their willingness to share their knowledge with the SoilMan research team.

The authors are also grateful to the two anonymous reviewers and to Editor Bettina Bock for their comments which considerably helped to improve the quality of the manuscript.

The SoilMan project (grant number 01LC1620) was funded through the 2015-2016 BiodivERsA COFUND call for research proposals, with the national funders Federal Ministry of Education and Research (BMBF), The French National Research Agency (ANR), The Swedish Research Council for Environment, Agricultural Sciences and Spatial Planning (FORMAS), Ministry of Economy and Competitiveness (MINECO), Executive Agency for Higher Education, Research, Development and Innovation Funding (UEFISCDI) and Estonian Research Council (ETAG).

Morgane Hervé's PhD studies are granted by the French Environment and Energy Management Agency (ADEME) and the University of Rennes 1.

Any opinions, findings, conclusions or recommendations expressed in this paper are those of the authors and do not necessarily reflect the views of these institutions. 


\section{Conflicts of interest:}

There are no conflicts of interest.

Authors' contribution statement:

Because of the interdisciplinary nature and the European dimension of the study, the number of authors exceeds 4, including researchers from the fields of Ecology and Economy from Germany and France. This work is part of METH's PhD thesis. She was responsible for the sampling and analyzing of the full dataset as well as of the writing of the manuscript. Her contribution was under the supervision and with advice of her directors, DC, MR, MP and AN, who developed the theoretical framework and the study design. EP and RS organized, implemented and participated to analyze the focus groups. All authors contributed to the writing and the designing of the manuscript.

Data:

Data sharing is not applicable to this article as no new data were created or analyzed in this study (qualitative meta-analysis) and Research data are not shared (focus groups). 
KEYWORDS

Agriculture

Soil biota

Pragmatism

Plural values

Focus Group

Soil management

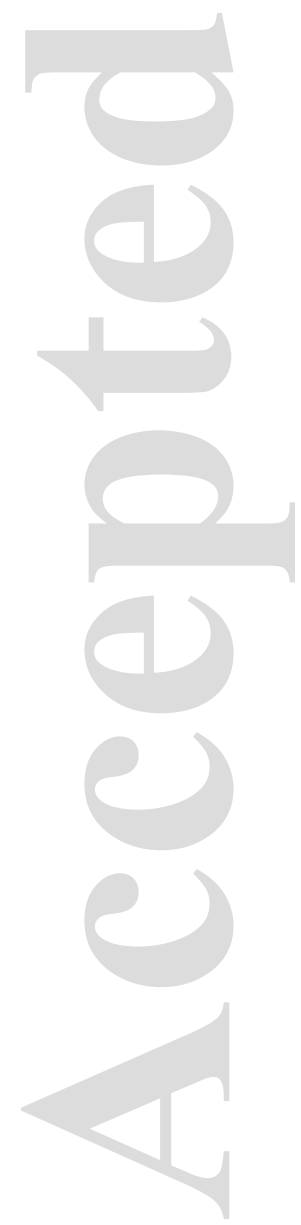


MISS MORGANE EVELYNE THÉRÈSE HERVÉ (Orcid ID : 0000-0003-0365-8521)

Article type : Original Article

\begin{abstract}
Agriculture benefits from soil functions, whereof many depend on soil biota, but some management practices can threaten soil organisms. We inventoried values that European farmers associate to soils and soil biota into their soil management decisions. We used Dewey's pragmatic epistemology, stating that values can be observed through active behaviours, attitudes and communication acts. We applied a plural values framework on a dataset composed of 35 scientific articles and five focus groups. Farmers addressed soil as a single object but hardly identified its biological elements, that appeared poorly known and little valued. Besides instrumental values, many other values, such as soil ecosystem resilience, influence farmers' management choices. We conclude that soils and soil biota values are plural and that they can evolve along with changes in farmers' practices. Further studies investigating values dynamics in time and space could be beneficial for designing an effective European soil conservation policy.
\end{abstract}

\title{
Key-words
}

Agriculture

Soil biota

Pragmatism

Plural values

Focus Group 


\section{Introduction}

Soil represents a thin layer of finely fragmented rocks and decomposed organic materials at the basis of most terrestrial ecosystems (Whalen and Sampedro 2010). Many soil functions depend on the functional diversity (Kardol et al. 2016) and the response diversity (Ludwig et al. 2018) of soil biota. While soils and soils functions play a major role for human activities (Wall et al. 2005), soil degradations have been reported worldwide since the early 90's (e.g., Oldeman 1992). At European scale, agricultural activities occupy $40 \%$ of the soils (Eurostat 2015). Because soils are not renewable at the scale of several human generations, avoiding their degradation, in particular in agriculture, has become a central issue (Powlson et al. 2011). Agricultural land managers like farmers are key actors to be addressed for soil preservation since their management decisions determine how the soil will be affected (Doran 2002). This paper, therefore, looks into values that are at the basis of farmers' engagement in soil management, which encompasses various practices $e . g$. soil tillage (including a range of practices from ploughing to soil conservation, like direct seeding), irrigation, fertilisation, crops rotations, crops diversification or grazing. Sustainable management of agroecosysems links their ecological resilience with economic and sociological dimensions of socio-ecosystems (Milestad and Hadatsch 2003). While the sustainability of agricultural production relies on practices that preserve soil ecosystems and associated functions (Plaas et al. 2019), inadequate management practices may impact soil biota (Thiele-Bruhn et al. 2012).

It is widely recognised that people's actions or practices at a given moment only partially reflect their value system and that external constraints and influences also contribute to their decisionmaking. Hence, social sciences have extensively studied factors influencing the selection of soil management practices by farmers, e.g., in the context of adopting new conservation farming practices (Goulet and Vinck 2008; Prager and Posthumus 2010). Economic considerations have an important influence on farmers' choice to adopt or to reject agro-environmental measures (Wilson and Hart 2000; Siebert et al. 2006) or to change their soil management practices (Brussaard 2012), e.g. to lower expenses (Ingram 2010) (for labour, machineries and material, fuel). De Krom (2017) identified this as "productivist" norms and dispositions. However, at European scale, it has been observed that farmers' behaviour rather consists of " $a$ mix of personal, socio-cultural, economic, institutional and even environmental variables" (Prager and Posthumus 2010). Social networks and interactions also influence farmers' practices 
(Compagnone 2014; Compagnone and Hellec 2015). Perceptions, beliefs (Prager and Curfs 2016), knowledge (Compagnone et al. 2008) and the social dimensions of learning processes (Ingram 2010; Ingram et al. 2010) are important drivers. Soil management practices also appear to carry some meaning for farmers' professional identity and shared norms (e.g., Compagnone and Pribetich 2017). For Bager and Proost (1997), farmers' environmental behaviour partly depends on a number of values that play a role in setting their priorities. However, this plurality of values at stake in farmers' decisions was not yet explored for soil biota and in relation to soil management.

The pragmatist epistemology of values developed by John Dewey (1939) embeds values formations in a given geographical, institutional, and cultural context, and stresses the role of social inquiry in values formation (Renault 2012). Defining values as what matters to people, what they feel attached to and therefore what they will care for (Renault 2012), we capture farmers' relationships with soils and soil biota within concrete situations rather than determining which external constraints and influences affect farmers' attitudes and behaviours. Farmers tend to start talking about their relation with nature by "what [they] were doing on the farm" (Boonstra et al. 2011), as their perception of biodiversity is strongly related to their daily life (Kelemen et al. 2013). We consider words, manners of speaking of farmers talking about their soil management to reflect values related to soils and soil biota which are revealed through the inquiry process. We designed an original methodology to gather those values combining a metaanalysis of qualitative data (Greenland and O' Rourke 2008) and Focus Groups discussions with European farmers. Investigating farmers' values appears essential to improve our understanding of their soil management practices and of the way in which they care about soils and soil biota.

\section{Theoretical background}

For long, ecosystems have been considered, at least in western and Judaeo-Christian cultures, as elements to be dominated and used by human-beings in order to address their own needs (Minteer 2005; Renault 2017). It has led to a dominant dualistic anthropocentric perspective in which nature is separated from humanity, the first being valuable to the second for the benefits it may provide, e.g., primary products, well-being, and aesthetic satisfaction (Bourdeau 2004; Elliot 1995). Monetary valuations of nature rely on this conceptualisation and they have encountered an important development among academics over the last decades. They are 
perceived as facilitating comparisons between goods and services emerging from the natural capital in opposition to those provided by other forms of capital (social, physical) (Maris 2015). Monetarisation of nature's benefits is also seen as useful tools to present trade-offs in management decisions (Salles 2011). An example related to soils can be found in Pascual et al. (2015) who proposed to evaluate the insurance value of soil biodiversity on the basis of (expected) profits. Moreover, Plaas et al. (2019) evaluated the effect of earthworms' functions considering winter wheat standard gross margin. Yet, economic valuation of nature or biodiversity, particularly in monetary terms, has been presented as a limited way to embrace the plurality of the human-nature relationships. Indeed, it homogenises the expression of values in one dimension, using the monetary unit, which is neither a standardised nor neutral unit, and may have important impacts on policy making (Maris 2015; Maris and Réveret 2009).

\section{Environmental ethics}

Environmental ethics have developed from the early 70s as an answer to social movements and a growing awareness on environmental issues brought to light by philosophers who addressed the moral considerability of nature (Larrère 2010; McShane 2009), independently from the use of nature for humanity's sake only. Different theories have emerged from this field, sometimes with deep oppositions (Létourneau 2010) e.g., human-centered ethics vs those considering species or ecosystems as valuable for themselves, independently from human needs (biocentric, ecocentric approaches). More extensive reviews on the main philosophical schools can be found for instance in McShane (2009), Larrère (2010), and Palmer et al. (2014). In summary, these classical environmental ethics theories have encountered much criticism addressing their lack of efficiency when it comes to provide operational answers to environmental issues (Létourneau 2010). Resulting from these concerns, environmental pragmatism has emerged in the middle of the eighties. In his founding paper based on John Dewey's epistemology, Weston (1985) stressed the dynamic, interrelated and plural nature of values which are constantly evolving within changing situations hence contesting the separation between ends and means. Environmental pragmatism was presented as a way to overcome crystallised theoretical debates in environmental ethics, particularly between those who advocated marked dichotomies e.g., anthropocentric vs non-anthropocentric values, intrinsic vs instrumental values (Rosenthal and Buchholz 1996), and thereby to be more practically effective. 


\section{Dewey's pragmatism}

While, originally, American pragmatist philosophers' work did not focus on the issue of nature per se, several of their epistemological positions were relevant for environmental ethicists (Parker 1996; Rosenthal and Buchholz 1996): pragmatism (1) defines organisms' experience as the result of transactions between them and their surrounding environments, (2) recognises values as dynamic, situation-dependent properties emerging from such transactions, (3) considers that the human beings' sphere is embedded in a larger natural sphere, both interacting and coevolving and (4) states that human beings develop a knowledge that structures the way in which they perceive the world. This represents an important break with approaches based on dualistic epistemologies in which thought and action, mind and body are separated (Armitage 2003; Renault 2016). Values are attributed under certain conditions and with certain consequences to an event, an object or a person (Dewey 1939, Renault 2012): they are objective in a given situation (Dewey 1939). Hence, values, are not exogenous, un-rational or fixed cultural elements pre-existing to action; they consist of observable and dynamic facts and result from the definition of desirable ends in problematic situations (Bidet 2008; Bidet et al. 2011) by a "desiring intelligence" (Mitchell, 1945). They reflect an appreciation that leads the individual to act in response (to reject, to take care...) and to produce evaluative discourses (Bidet et al. 2011). Values are expressed through active behaviours and attitudes; they are also subjected to reflexive examination and can be detected through the reasoning and the formulating of the evolving objectives for actions i.e. within communication acts (Bidet et al. 2011).

3. Values plurality in environmental pragmatism: using a "taxonomy" of values 1 Pragmatism integrates the plurality of meanings actors might attach to a given object when investigating values (Renault 2016). Hence, values plurality is a key-stone concept of environmental pragmatism (Callanan 2010). Plural values encompass the 'multiple ways in which nature, ecosystems or ecosystem services are important for individuals or social groups' (Arias-Arévalo et al. 2018). Values plurality has been described as the best way to reflect on and to conjugate diverse dimensions of human-nature relationships (Van Riper et al. 2017), and to potentially strengthen protection or conservation measures (Larrère 2010). Decaëns et al. (2006) provide examples of the various ways in which soil biota could be valued for conservation. Weston (1985) stated that pragmatism, by considering interrelated, interdependent and dynamic 
values, allows for forming "a kind of 'ecology' of values". Along this line, we used the taxonomy of values from Arias-Arévalo et al. (2018) (Fig. 1) to describe a "community" of interacting values related to agricultural soils and soil biota in Europe, referring to the concept of "species community" in ecology (McIntosh 1985).

Place Figure 1 around here

\section{Material and methods}

This study is part of the European BiodivERrsA research programme "SoilMan" (https://www.soilman.eu/), running from 2017 to 2020. This programme is implemented in five regions covering a great variety of geographical contexts along a double gradient (latitudinal and longitudinal, Fig. 2). "SoilMan" studies the impact of soil management practices on soil biota functions and subsequently the economic impact at farm scale. It also examines how farmers value soil biota and how these values can be integrated in European policy and regulation. The researchers belong to a wide range of disciplines in natural and human sciences: soil ecology, soil physics, ecological statistics, agriculture economy and socio-economy.

A first pan-European value inventory of soils and soil biota was implemented using a three-step design (Fig. 2). In the first step we collected data about farmers' management practices decisions (i) in pre-existing literature and (ii) in five Focus Groups (FGs) we organised with farmers. We constructed our own two data sets, one based on the FGs and one for the meta-analysis of scientific literature. A second step consisted in collecting quotations that illustrate how soil and soil biota mattered to farmers. Environmental pragmatism devotes a large space to "inclusive, collaborative discourse in the evaluation and justification of practices and policies" (Palmer et al. 2014), considering that values can be investigated through language and communication acts (Létourneau 2010). Thus, we considered the descriptions and explanations of soil management choices by farmers as an active expression of their values for soils and soil biota in specific situations. In a third step we then translated the quotations we collected into a list of frequently mentioned values using the typology proposed by Arias-Arévalo et al. (2018). In the following, we explain the three steps more in detail.

Place Figure 2 around here

1. Values emanating from scientific literature across EU within the last 25 years 
We performed an analysis of the existing body of literature, using a qualitative meta-analysis approach (e.g., Lastra-Bravo et al. 2015). A meta-analysis can be performed on multiple scientific studies addressing the same overarching question (Greenland \& O' Rourke 2008) usually to identify patterns among quantitative results. We based our qualitative meta-analysis on raw quotations or authors reporting farmers' opinions. Hence, we did not review previous conclusions from the surveyed literature but executed a secondary analysis of the qualitative data presented in those studies.

The meta-analysis included current studies on farmers' soil management, collected in peerreviewed and academic publications i.e., articles in scientific journals, books chapters, and $\mathrm{PhD}$ theses. Scientific literature was searched in the Web of Science database as well as in Google Scholar using the words "soil”, "farmer", "value", "environmental value”, "soil biodiversity", "representation", “perception", “agriculture”, and "management decision”. Documents were preselected when the title indicated that either the farmer's decision-making, environmental behaviour or soil management practices, such as (1) no tillage, (2) soil tillage, (3) cover crops use, (4) crops rotation or (5) fertilisation, were addressed. Studies directly investigating values related to soils or soil biodiversity were rare; most studies were designed according to socioeconomical or behavioural approaches, and only few were based on environmental ethics philosophy. Papers that did not present how farmers view their practices were excluded from our dataset. The final dataset was composed of 35 documents written between 1996 and 2018 (Supp. Mat. 1). It included studies from in 15 European countries, and three documents presented panEuropean studies. Although literature dealing with farmers' practices and behaviour has been written in earlier periods, soil or values were not tackled or the values were not extractable and therefore these documents could not be used.

2. Inventory of current values related to agriculture soils and soil biota in Europe Focus Groups are "a semi-structured group session, moderated by a group leader, held in an informal setting, with the purpose of collecting information on a designated topic" (Carey and Smith 1994). Their main aim "is to understand, and explain, the meanings, beliefs and cultures that influence the feelings, attitudes and behaviours of individuals." (Rabiee 2004). A FG is different from a group interview as the moderator facilitates a discussion between the participants and engages as little as possible with the discussion in order not to interfere with the 
relationship they develop (Parker and Tritter 2006). For the time spent, FGs are very effective tools to gather a substantial amount of qualitative data (Parker and Tritter 2006) and they are commonly used in agriculture research (e.g., Roesch-McNally et al. 2018). Following Dewey's (1939) pragmatist epistemology, we collectively define what is desirable through communication. FGs, hence, appeared as a relevant tool to uncover values while allowing farmers to discuss and collectively reflect on what matters to them.

Five FGs were organised, one in each of the five countries involved in SoilMan, during winter 2017-2018 to complement data collection. Farmers were recruited either by the local researchers' network or with the help of the local agriculture advice organisation (Tab. 1). A monetary reward was proposed in order to increase the chances of acceptance to participate. All farmers who participated have their farm in one of the studied regions of the "SoilMan" programme and their crop rotations include wheat. We first invited farmers whose fields served for biodiversity analyses within "SoilMan"; then this sample was extended to farmers who were not involved in the programme and therefore potentially less aware of or interested in soil biota issues. The sampling strategy was progressively extended according to the response rate because we needed to control the number of participants of the groups. The composition of some groups was homogenous, not reflecting the regional heterogeneity of farming practices. For instance, in the French FG all participating farmers were involved in conservation tillage as we did not succeed in recruiting other farmers. It is likely that in such situations, the variety of opinions may be low, which can limit the debate. Yet, homogeneous composition within groups may facilitate exchanges between participants (Krueger and Casey 2009) as they can have the feeling they are alike and start a discussion more easily. We considered it particularly important for setting FG with farmers who have never met before.

\section{Place Table 1 around here}

Each FG started with a presentation of all participants, researchers included. Then the moderators took some minutes to present the "SoilMan" programme and the thematic of the discussion. Then farmers were asked to describe their farm, their crops rotations, their current management, the constraints they identify for their farming activity and the way they cope with them as well as the opportunities they perceive. Questions asked in the FG were non-constraint in order to observe how farmers present their management practices and choices and to facilitate collective exchanges. In doing so, we were confident that farmers would be able to reflect on 
what they want or like to do and why (Floux and Schinz 2003). At the end of the FG, farmers were asked to fill in a questionnaire to collect sociodemographic data and more information about their farm. Foods and drinks were offered and farmers were invited to stay after the meeting to share a convivial time if they wished to. For each FG, at least one observer was present in order to manage the sampling material and to take complementary notes on farmers' behaviour or particular gestures. The role of the observer is important to help interpret some expressions and sentences or to detect particular social interactions that would influence the expression of certain values. Just as with the literature dataset, values were not directly addressed, but rather detected later through farmers' engagement in the description of their practices and the explanations of their management decisions.

The FGs lasted roughly 2 hours each and they were transcribed and translated into English. The material we used to investigate values consists of quotations from these transcripts.

\section{Data analysis}

Data was qualitatively analysed, which is particularly well adapted for exploratory studies (Yuhas Byers and Wilcox 1991). The method consisted of tracing back the decision-making process in the specific situation of each farmer, described in their narratives in the FGs or in the collected studies (literature dataset). We inferred values by interpreting the reasons that the farmers state for implementing a management practice in the light of Arias-Arévalo's (2018) definitions and taxonomy of values.

Transcripts of the FGs and documents of the literature dataset were entirely read a first time in order to get a general overview. For both, a second reading focused on the parts in which soils or soil management practices were addressed, which were then extracted. For the FG dataset, we collected raw quotations from the discussion between farmers. Following Parker and Tritter (2006), we also considered whether the farmer answered a direct question or remark from the moderator or responded to another farmer to complete or to oppose his/her words for the interpretation. From the meta-analysis of scientific literature, we extracted raw quotations when available or authors' transcriptions of farmers' explanations and choices. At that stage, selected quotations from the FGs and the literature survey were characterised following an inductive coding ultimately addressing practices, explanations, and farms and situations characteristics and completed our datasets. The third step consisted of categorising values at stake in the selected 
quotations using Arias-Arévalo et al.’s (2018) typology of values (Fig. 1). Finally, we obtained a number of practice choices or statements about soils, the underlying reasons, the value we associated to them and either the quotations from the FGs or a reference to the documents obtained by the literature survey (see Supp. Mat.1,2).

\section{Results}

In the literature and in the focus groups we could identify ten different values belonging to all four value domains defined by Arias-Arévalo (2018): intrinsic and instrumental values, four fundamental and three eudaimonistic values (Fig. 3). Besides the economic importance of soils and its organisms for agricultural production, farmers also value processes in the ecological system and various dimensions of their relationship with soils which sustain their professional activity and their well-being. In general, farmers addressed soils as a whole system, seldom expressed values for soil biota and never considered soil biological diversity. In the FGs, farmers tended to interact by comparing the characteristics of the region in which they are situated or their respective practices, and by asking each other some technical details about their farming system. Farmers did not explicitly focus on values per se. This is not surprising: the FGs were designed to gather information about what matters when implementing practices, without directly referring to the concept of values.

Place Figure 3 around here

\section{Values of soil biota}

When soil biota was valued for ecological resilience, farmers recognised their role in soil functioning and chose management methods that they considered adequate for soil organisms. For instance, farmers linked the importance of earthworm preservation in their soils to organic matter degradation and to benefits for their production.

"[...] the group of Hungarian conventional farmers named ecosystem services useful for agriculture, such as pollination and decomposition, on the concept map as the most important benefits provided by biodiversity. 'In order to have orchids or good quality hay on your fields, all these things (worms and pollinators) are needed.' (HU conv)" Kelemen et al. (2013, p.323)

As such, earthworms were qualified as a real "livestock" to be fostered in farm's soils (Supp. Mat. 2): 
I just said, my $C I P A N^{2}$, between two cereal crops, it is a real dérobée $e^{3}$, excepted that while some people might harvest it for cattle feeding, I leave it on the soil for my earthworms. And they are super important. I guess you are going to talk about that, but this earthworm livestock needs to be fed, because if we don't bring them food, they will never develop neither. (FR-5)

Some farmers noticed a global development of awareness about the role of soil biota for the ecological resilience of soils ("There is an increasing awareness about soil life and its importance on the natural character of culture systems", FR-4, Supp. Mat. 2) and its potential use as an indicator to describe soil quality (Wahlhütter et al. 2016, Supp. Mat. 1). Through the integration of new farming concerns and purposes, indicators used to assess agriculture and farming practices can evolve over time and soil biota could become a criterion (e.g., Coll et al. 2012). Saunders (2016) enlarges this perspective by stating that "environmental action" itself can become a criterion defining a "good agriculture". Favouring soil biodiversity by their own practices can also become an element of pleasure for farmers indicating a meaningful activity value (Supp. Mat. 2):

Usually, it is only superficial tillage, but during autumn that is a real pleasure, it is fed, it is full of earthworms, we find them everywhere, this is the most impressive culture, we can't observe this as much after a forage corn. (FR-3)

In the Spanish FG one farmer explained how he organises ploughing in order to favour earthworms. As he does not explicitly link it to his production he potentially expressed a value that relates to the intrinsic domain, even though he remained quite vague on his motivations (Supp. Mat. 2):

Otherwise I plough very late in the season, perhaps also because I think of leakage and worms. You think about having a place where the worms can get down. And I, I don't, I imagine that they can find their way down if I prepare it for them. (SE-5)

In general, farmers expressed a limited knowledge of soil biota. Only few organisms, mainly earthworms, were mentioned (e.g., Kelemen et al. 2013, Supp. Mat. 1). In particular, farmers mentioned soil biota most frequently during the French FG (e.g., FR3, FR5, Supp. Mat. 2), where most participants actually use reduced tillage (Tab. 1).

2. Values of the soil system as a whole

\section{Instrumental value domain}

Overall, instrumental values attributed to the soils were widely spread in the dataset (Fig. 3C, D). Soil is valued as a support of production that should be managed in order to enhance 
profitability. In this case, soil conservation practices were economically valued for maintaining yields while limiting costs, time and workload (Supp. Mat. 2, see also Supp. Mat. 1):

I think there is a collective awareness about yield stagnation; the lack of labour availability in the farms, which is going to become a central issue within the next years, soil management workload will need to be reduced. (FR-5)

Some farmers decided to maintain ploughing because they perceive it as a tool to avoid soil compaction, which would damage crops and machineries (RO-5, Supp. Mat. 2). For some farmers the impacts of practices changes such as crops rotation complexification can be more costly e.g., in terms of workload. Yet such impacts are not always acknowledged, and therefore not integrated into production prices or subsidies amounts ("[...] we diversify [our cultures] as much as possible, we get a maximum workload, and we are less and less paid", FR-2, Supp. Mat. 2). Positive outcomes of practices for soil functioning can be perceived as beneficial in the longrun and then reinforce or legitimate farmers' decision (Supp. Mat. 1; 2):

\footnotetext{
We used to plough half of it and what pushed me to stop ploughing on the whole surface is the lack of labour. That was for this reason at the beginning, more than because of soil aspect, and afterwards I realised that it worked very well for the soil. (FR-2)

"Promoters and farmers alike recognise that the transition from ploughing to reduced tillage can be troublesome and that it takes time before the benefits are apparent [...]: 'We always claim that it takes at least three years to get this cycle going. Year one after you've ploughed the crops are usually good, year two you take a bit of a dip in yield because you've lost the good structure you had from ploughing yet you haven't got the natural structure or the worms but in year three yields start to go up again and of course an awful lot people bunk out after year two' (SMI13).” (Ingram 2010, p.192)
}

\section{Fundamental values domain}

Our results show that soil values can also directly relate to ecosystem resilience (Fundamental value domain, Fig. 3C, D). In the literature dataset, these values are linked to soil constitution as well as to the maintenance of its functions which can be achieved with a great variety of farming practices (Supp. Mat. 1, e.g., Compagnone et al. 2013, Schneider et al. 2010). In the FGs, for instance, maintenance of soil organic matter content was particularly important (Supp. Mat. 2):

I think we are going to perform a corn-wheat-rapeseed-wheat rotation, even if corn is not profitable. But regarding weeding, regarding the whole rotation, when we are going to produce corn, we are going to bring back material to the soil. (FR-3) 
Farmers were also aware of the soil's role in biological pest and disease control when implementing crops rotations on the farm ("In our case, when wheat culture follows wheat culture, we always use ploughing and generally use ploughing after wheat to prevent it from spreading, grass stocking, foot diseases...”, D1, Supp. Mat. 2). Very often resilient ecological functioning of soils appears to be important, because it ensures production in a long-term ("This [crop rotation] is important for soil fertility later on, and this is important to farmers, because that's our capital', D-8, Supp. Mat. 2).

Soil is also, directly or indirectly, a support of farmers' identity in the community as it can be at the basis of a shared definition of a "good farmer" (Supp. Mat. 1, 2), which can be also associated to a symbolic value (fundamental value domain, Fig. 3C, D). For instance, for a Romanian farmer his knowledge about his soils seems to be important to define his skills as a farmer in front of the group ("So far, I have not done agrochemical analyses, but I want to mention that I know my soil as much as I know the need of plants for nutrients", RO-8, Supp. Mat. 2). In the FGs, farmers described shared visions of soil management practices that should be used in a region ("[...] rationally speaking it is better not to have to plough so much. Yet, it is generally seen as something that is necessary", SE-2, Supp. Mat. 2). This can be associated to "traditional image of farming" (Schneider et al. 2010), from which cultural heritage values could stem. Social environment attributes cultural meanings and identity-building roles to agriculture practices:

\footnotetext{
"When it comes to social motivations, they focus on the emergence of a norm related to practices and shifting towards no-tillage application. Farmers notice that this practice is more and more applied in their professional environment, which confirm their idea to show interest for it too, and even to persevere when they have innovated in that direction (49-15-AC) (49-5AC-12). 'But well, what makes... I mean what pleases me a bit is that nowadays... [...] You feel like you were a little bit among the pioneers I mean [...]' (49-5-AC-12)." (Compagnone et al. 2013, p.152; shortened quotation) ${ }^{4}$.
}

\section{Eudaimonistic values domain}

Soils can support the cognitive development of farmers, who insisted on the deep mental transformation associated with a stable adoption of soil conservation practices (Eudaimonistic value domain, Fig. 3C, D). In the dairy farming region of Brittany (France) for instance, farmers described the adoption of reduced tillage methods as cognitively stimulating, because they can 
develop their own management decisions compared to their traditional farmer neighbours who consider soils as manure spreading and cattle feeding surface (Supp. Mat. 2):

- [...] historically we used to delegate and the technician from the cooperative used to come, and, for my parents it was "you apply that, you apply that", and it took that in charge, but I personally got interested because I like it and I realised you could increase the margins [....] But nowadays considering the workload in cattle breeding, the surfaces that have increased, a lot of farmers have delegated and they are not interested. They want a simple system: ploughing, sowing, and that's that. This is livestock farming. Soils are a support for manure spreading, and that's that.

- It [the soil] is a support of cultures, that's all. There is not even soil observation any more, when we adopt those practices, our perspective on soil and on cultures completely changes. (FR-1 and 5).

Farmers interviewed by Compagnone et al. (2013, Supp. Mat. 1) stressed the intellectual changes caused by a shift from a ploughing to a ploughing-free system and Ingram (2010, Supp. Mat. 1) showed that changing soil management practices can be satisfying as a challenge in terms of learning and knowledge development.

Our study also showed that soil ecosystems can carry meaningful occupational values (Eudaimonistic value domain, Fig. 3C, D). Farmers values related to the way they want to live and to work as farmers are related to soils: being autonomous, having qualitative production, being proud of a certain lifestyle:

“An IP farmer made a similar observation about organic farmers and commented: 'Today they know the soil and the techniques. They have to think and not just follow a treatment plan. That causes an improvement in quality' (IP).” (Home et al. 2018, pp.8-9)

Altruist values (Eudaimonistic value domain, Fig. 3D) were expressed by a farmer in relation to ploughing-free systems supporting global sustainability and carbon storage (Supp. Mat. 2):

Well, no, but basically if I understand research correctly then agriculture is a problem of the sustainable aspects of our planet. We let all this carbon out into the atmosphere and we don't sequestrate carbon. That would correspond to the amount of greenhouse gases that we let out. And I think that agriculture could be not only a way to produce food it could also be a way to repair lots of the main system that actually keeps us alive. (SE-5)

Intrinsic values related to soil were (i) absent from our literature dataset and (ii) barely expressed by farmers during the FGs, sometimes even absent, such as in France (Fig. 3C, D). Nevertheless, some management choices may be evaluated on the basis of expected positive effect for soil biota (Supp. Mat. 2): 
The more soil cultivation is done, no matter in which form, the fewer earthworms there are. When it comes to tillage, also in depth, the more earthworms we have. That's why we all like to do little tillage. (D-13)

\section{Discussion and conclusion}

Thanks to a comprehensive dataset composed of farmers' narratives on soil management deriving from a meta-analysis of scientific literature and focus groups discussions, we captured a great variety of values that play a role in farmers' decision-making and concerns for soil management in Europe.

1. Values plurality of soil biota and soils

\section{Instrumental values}

Soils and soil biota were found to be of instrumental value. In a highly subsidised and homogenised agricultural system, it is easier to use productivity to compare farming performance in a short term (Burton 2004); other values may seem more difficult to use for comparing oneself to other farmers. This could also be rooted in a productivist paradigm placing production levels as the sole reference for evaluating the success of agriculture (Thompson 1995). Based on our results, the adoption of environmentally-friendly soil management practices was primarily influenced by economic considerations, whereas soil biota conservation appears to be of secondary importance. Yet, farmers appreciated practices integrating environmental benefits as well. Prevailing instrumental values do not exclude the existence of other values related to the soil such as the importance of ecological resilience and farmers' identity.

\section{Fundamental values domain}

Farmers from the FGs were aware that their management influences the functioning and the resilience of soil ecosystems. The relevance of ecological resilience values confirms the results from other studies showing that beliefs about conservation effects on soil structure and functioning influence farmers' practices (Werner et al. 2017).

Similarly, to ploughing which can carry identity values, reduced tillage also contributes to farmers' professional identity (Goulet and Chiffoleau 2006). This illustrates the unfixed character of farmers' professional identity that can be questioned (Deuffic and Candau 2006) and redefined (Riley 2006). Farmers' professional identity may also rely on their ability to integrate 
ecological perspectives when managing soils. Some farmers may integrate society's expectations in their soil management (Supp. Mat. 1) too. Thus, valuation regarding soils in particular is also informed by the societal definition of what matters in agriculture. But farmers set different priorities on their farm (e.g. Greiner et al. 2009) which opens the door for questioning how some values come to prevail over others.

\section{Eudaimonistic values domain}

A great variety of complex interacting processes takes place in soils with farmers needing assistance in taking relevant management decisions (Watson et al. 2002). Soil management changes do not only question farmers' identity, they encourage them to consider new aspects of soils, beyond a simple crop support, which can be challenging but also rewarding. Regarding weed-management, which is highly influenced by social interactions and shared symbols depicting "a good farmer", Sutherland et al. (2012) found that the cognitive development is crucial when shifting practices. Indeed, the productivist model that has been favoured since the 60s would require less knowledge (Rivaud and Mathé 2011). Farmers tend to consider independence as important (e.g. Greiner et al. 2009) yet, in France for instance, they have become more dependent on the assistance of technical advisors (Rivaud and Mathé 2011). We hypothesise that new soil management practices represent a challenge that may help farmers to reengage in the complexity of farming and create a satisfying feeling of autonomy in their professional occupation.

\section{Focus on soil biota values}

We considered that valuation processes take place along with soil management practices, and values were expressed in farmers' communication about these practices. Our approach was original in that it (i) introduced a precise framework for values definition and investigation, (ii) considered plural potential values dimensions associated with soils at once and (iii) focused on soil biota itself and not only on soil or on management practices. Our results show that farmers attach a plurality of values to soil but to a less extent to soil biota. Farmers addressed soils mostly as a system and hardly distinguished between its biological elements. Organisms that appeared to be known and valued were mostly limited to earthworms. Pauli et al. (2016) described spiritual and sacred knowledge related to soils or soil biota in subsistence farming 
systems from different regions of the world (e.g., Southern Africa, Central America) but they barely got such information in European systems. We did not detect values of sacredness, aesthetics or spirituality neither concerning soil biota nor soil as a whole even though such values have been recorded elsewhere in Europe (Cooper et al. 2016). Already 25 years ago, Thompson (1995) described a dominant conception of "depersonalized, liveless" soils e.g. in the EU, even if modern agriculture would have acknowledged, to a limited extent, the role of soil organisms for soil functioning.

\section{Situation considerations in values formation}

In a pragmatist epistemology, individuals lead an inquiry which allows them to progressively capture the whys and wherefores of problematic situations (Bidet 2008). Valuation operates when desirable ends are defined to solve a problem, considering available means (Dewey 1939). Farmers provide quite precise details on the characteristics of situations that they have to integrate in their management decisions e.g. weather (Werner et al. 2017) and price variations on the global crop market (Posthumus et al. 2011). In their responses, they seek to maintain their flexibility to react to external constraints and their adaptability to cope with unpredictable events (e.g., Schneider et al. 2010). In doing so, they evaluate the outcomes of practices e.g. by giving importance to an "adequate and secure income rather than profit maximization at any cost" (Dury et al. 2013). Hence valuation processes are not restricted to soils and soil biota objects. In that regard, conflicts of values are likely to occur and it would be relevant to further investigate how farmers address them.

Since situations are not static, values may evolve, influenced by exchanges and confrontation with other individuals as well (Létourneau 2010). And indeed, farmers participating in our FGs explained that social interaction facilitates the adoption of new practices (Supp. Mat. 2) which was also shown for adopting agro-environmental measures (Rivaud and Mathé 2011) and soil conservation practices (Franco and Calatrava 2012). For future research, we suggest case-studies to capture (i) how farmers investigate problematic situations (why is it problematic, which causes do they identify and how do they characterise them, how does that question their usual habits?), (ii) how they define objectives to solve this problematic situation (how do they define what is desirable, on the basis of which criteria, and how do they consider the relevancy of a mean?) and (iii) how valuation may evolve in changing situations and along communication acts. 
3. Comments on the methods and on the approach

Our dataset was composed of different studies: (i) on various production systems, e.g., intensive or extensive agriculture, (ii) combining various sampling strategies (iii) mainly on soil management and conservation, and (iv) a few focusing on the implementation of agroenvironmental measures regarding soil aspects. Scientific documents could be used in this metaanalysis as long as they adequately linked results to interpretations. This was actually our main issue when collecting data because (i) a lot of studies had a constraining design, i.e., pre-defined statements or questions limiting farmers' freedom of answer and therefore preventing them to express their concerns in their own words; (ii) reasons associated with farmers' decisions were not always clarified or explained, in particular in the case of soil issues. Another challenge was that soil is sometimes valued as an intermediary among a chain of successive values. In a pragmatist epistemology, this is qualified as a continuum of ends-in-view and means. For instance, in Kaltoft (1999), farmers' care about soil is translated into their management practices but this interlinks with further objectives in terms of production. Our results show that qualitative meta-analysis can be a relevant tool to analyse value systems and can increase sample size, especially for studies at large scale. While we think that going in the studied region and listening directly to farmers is a real asset, applying the FG method at a European level in five countries has been challenging. Moderation had to be delegated to local members of the "SoilMan" programme because of the language barrier. Common guidelines allowed standardising the process. Data collection still varied with group dynamics, of which the moderators were an integral part. All moderators had previous knowledge related to soil or agriculture and the "SoilMan" programme as a common background. This helped to clarify the objectives and to focus on topics particularly relevant for the studied areas. In a few cases, after translating the transcript, we realised that it would have been interesting to deepen the investigation of some items. Therefore, collective training has to be carefully considered for organising FGs, especially when working in interdisciplinary research teams and this should not be underestimated. Yet, we are convinced that once shared expectations are reached, different and complementary expertises are a real asset to moderate FGs. The second challenge lied in the translation of the FGs content. We asked native speakers who were familiar with the soil topic to transcribe the FG discussion in their native language and then to translate it into English. Except for Sweden, all translators also 
attended the FGs and witnessed the discussion which assisted both the transcription and the translation steps.

\section{Conclusion and perspectives}

The pragmatist epistemology proposed by J. Dewey stresses the recognition of values as observable facts revealed through communication acts. Authors who have adopted this perspective insist on the need to recognise the plurality of ways in which nature can be valued (e.g. Larrère 2010; Létourneau 2010). Values plurality encompasses stakeholders' variety of perspectives on a topic (van Riper et al. 2017) providing elements to better integrate socioecosystems complexity into policy and land management (Jacobs et al. 2016). This article proposes an operational application of the pragmatic epistemology to analyse soils and soil biota values in Europe in the agro-environmental field. Constructing our dataset on these foundations, we used existing literature and implemented focus groups. Rather than focusing on one type of value, our study design allowed for the collection of multiple values associated with soils and, specifically, with soil biota in Europe. In the end, we obtained a list of observable soil and soil biota values across Europe (an inventory so to say) based on farmers' discourse. It suggests that eluding several of these values to focus only on one dimension (i) should be justified as it might only partially reflect farmers' relationship with their soils and (ii) could limit the significance of scientific studies and policy recommendations. At the scale of the European Union, the integration of diverse human-nature relationships is seen as a major challenge for the next 30 years of environmental protection policies (van Zeijts et al. 2017). Our original methodology and the environmental pragmatism epistemology provide an operational tool for investigating human-nature relationships, which will help to develop strategies for ecological transition in agriculture.

More precise investigations should focus on farmers' values in their "specific national histories and agricultural constitutions and the societal, political and economic environment" (Siebert et al. 2006). Along with Dewey's theory (1939), which defines values and valuation processes as a cultural phenomenon, values analysis has to be done according to the social and cultural context in which they appear (Bidet et al. 2011). Therefore, the following step of this work should look into the spatial variations of the inventoried soils and soil biota values. 


\section{Endnotes}

1. Term used by Arias-Arévalo et al. (2018) to name their typology of values of nature and ecosystem services.

2. "Culture Intermédiaire Piège A Nitrates" i.e., intermediate culture between two other cultures aiming to capture nitrogen.

3. An intermediate culture between two main crops which is also expected to be economically profitable.

4. Translation from the authors, original version in French.

\section{References}

Arias-Arévalo, P., E. Gómez-Baggethun, B. Martín-López and M. Pérez-Rincón (2018) Widening the Evaluative Space for Ecosystem Services: A Taxonomy of Plural Values and Valuation Methods. Environmental Values 27 (1) pp. 29-53

Armitage, K.C. (2003) The Continuity of Nature and Experience: John Dewey's Pragmatic Environmentalism. Capitalism Nature Socialism 14 (3) pp. 49-72

Bager, T. and J. Proost (1997) Voluntary Regulation and Farmers' Environmental Behaviour in Denmark and The Netherlands. Sociologia Ruralis 37 (1) pp. 79-96

Bidet, A. (2008) La genèse des valeurs : une affaire d'enquête. Tracés 15 pp. 211-216

Bidet, A., L. Quéré and G. Truc (2011) Introduction. Pp. 5-64 in A. Bidet, L. Quéré and G. Truc eds., Ce à quoi nous tenons. Dewey et la formation des valeurs (Paris: La Découverte)

Boonstra, W.J., J. Ahnström and L. Hallgren (2011) Swedish Farmers Talking about Nature - A Study of the Interrelations between Farmers' Values and the Sociocultural Notion of Naturintresse. Sociologia Ruralis 51 (4) pp. 420-435

Bourdeau, P. (2004) The man-nature relationship and environmental ethics. Journal of Environmental Radioactivity $72(1-2)$ pp. 9-15

Brussaard, L. 2012. 1.3 Ecosystem Services Provided by the Soil Biota. Pp. 45-58 in D.H. Wall, R.D. Bardgett, V. Behan-Pelletier, J.E. Herrick, T.H. Jones, K. Ritz, J. Six, D.R. Strong and W.H. van der Putte eds., Soil ecology and ecosystem services (New York, NY: Oxford University Press)

Burton, R.J.F. (2004) Seeing Through the "Good Farmer's” Eyes: Towards Developing an Understanding of the Social Symbolic Value of "Productivist" Behaviour. Sociologia Ruralis 44(2) pp.195-215

Callanan, L.P. (2010) Intrinsic Value for the Environmental Pragmatist. Res Cogitans 1(1) pp.132-142

Carey, M.A. and M.W. Smith (1994) Capturing the Group Effect in Focus Groups: A Special Concern in Analysis. Qualitative Health Research 4 (1) pp. 123-127

Coll, P., R. Le Velly, E. Le Cadre and C. Villenave (2012) La qualité des sols : associer perceptions et analyses des scientifiques et des viticulteurs. Etude et gestion du sol 19 (2) pp. 79-89

Compagnone, C. (2014) Burgundy Winemakers and Respect for the Environment Occupational Networks and the Dynamics of Change. Revue Française de sociologie 55 (2) pp.245-279 
Compagnone, C. and F. Hellec (2015) Farmers' Professional Dialogue Networks and Dynamics of Change: The Case of ICP and No-Tillage Adoption in Burgundy (France). Rural Sociology 80 (2) pp. 248-273

Compagnone, C., F. Hellec, K. Macé, P. Morlon, N. Munier-Jolain and L. Quéré (2008) Raisonnement des pratiques et des changements de pratiques en matière de désherbage : regards agronomique et sociologique à partir d'enquêtes chez des agriculteurs. Innovations Agronomiques 3 pp. 89105

Compagnone, C. and J. Pribetich (2017) Quand l'abandon du labour interroge les manières d'être agriculteur. Changements de norme et diversité des modèles d'agriculture. Revue Française de Socio-Économie 18 pp. 101-121

Compagnone, C., A. Sigwalt, J. Pribetich, E. Dumont and V. Lucas (2013) QueSacteS. QUEstionnement Sociologique sur la perception que les Agriculteurs et les Conseillers Techniques ont des Sols. Final Research Report - GESSOL program (Dijon, FR : Agrosup)

Cooper, N., E. Brady, H. Steen and R. Bryce (2016) Aesthetic and spiritual values of ecosystems: Recognising the ontological and axiological plurality of cultural ecosystem 'services'. Ecosystem Services 21 (Part B) pp. 218-229

Decaëns, T., J.J. Jiménez, C. Gioia, G.J. Measy and P. Lavelle (2006) The values of soil animals for conservation biology. European Journal of Soil Biology 42 S23-S38

Deuffic, P. and J. Candau (2006) Farming and Landscape Management: How French Farmers are Coping with the Ecologization of Their Activities. Journal of Agricultural and Environmental Ethics 19 (6) pp. 563-585

Dewey, J. (1939) Theory of valuation. Pp. 1-67 in O. Neurath, R. Carnap and C.W. Morris eds., International Encyclopaedia of Unified Sciences Vol. II n4 (Chicago, IL: The University of Chicago Press)

Doran, J.W. (2002) Soil health and global sustainability: translating science into practice. Agriculture, Ecosystems and Environment 88 pp. 119-127

Dury, J., F. Garcia, A. Reynaud and J.-E. Bergez (2013) Cropping-plan decision-making on irrigated crop farms: A spatio-temporal analysis. European Journal of Agronomy 50 pp. 1-10

Elliot, R. (1995) Environmental ethics (Oxford, UK: Oxford University Press)

Eurostat (2015) Land use statistics. https://ec.europa.eu/eurostat/statisticsexplained/index.php?title=Land_use_statistics. Eurostat, Statistics Explained. Accessed 12 November 2018

Floux, P. and O. Schinz (2003) "Engager son propre goût", entretien autour de la sociologie pragmatique d'Antoine Hennion. ethnographiques.org 3

Franco, J.A. and J. Calatrava (2012) The diffusion of no-tillage with herbicides application in Southern Spain's olive groves. Journal of Environmental Planning and Management 55 (8) pp. 979-1003

Goulet, F. and D. Vinck (2008) Innovation through Withdrawal Contribution to a Sociology of Detachment. Revue Française de sociologie 53 pp. 195-224 
Goulet, F. and Y. Chiffoleau (2006) Réseaux d'agriculteurs autour de l'agriculture de conservation en France : Echanges de savoirs et identités. Presented to the Troisièmes rencontres méditerranéennes du semis direct, Saragosse, March 23-25, 2006

Greenland, S. and K. O' Rourke (2008) Meta-Analysis. P. 652 in K.J. Rothman, S. Greenland and T. Lash eds., Modern Epidemiology (Philadelphia, PA: Lippincott Williams and Wilkins)

Greiner, R., L. Patterson and O. Miller (2009) Motivations, risk perceptions and adoption of conservation practices by farmers. Agricultural Systems 99 (2-3) pp. 86-104

Home, R., A. Indermuehle, A. Tschanz, E. Ries and M. Stolze (2018) Factors in the decision by Swiss farmers to convert to organic farming. Renewable Agriculture and Food Systems 34 (6) pp. 571581

Ingram, J. (2010) Technical and Social Dimensions of Farmer Learning: An Analysis of the Emergence of Reduced Tillage Systems in England. Journal of Sustainable Agriculture 34 (2) pp. 183-201

Ingram, J., P. Fry and A. Mathieu (2010) Revealing different understandings of soil held by scientists and farmers in the context of soil protection and management. Land Use Policy 27 (1) pp. 51-60

Jacobs, S., N. Dendoncker, B. Martín-López, D.N. Barton, E. Gomez-Baggethun, F. Boeraeve, F.L. McGrath, K. Vierikko, D. Geneletti, K.J. Sevecke, N. Pipart, E. Primmer, P. Mederly, S. Schmidt, A. Aragão, H. Baral, R.H. Bark, T. Bricenon, D. Brogna, P. Cabral, R. De Vreese, C. Liquete, H. Mueller, K.S.-H. Peh, A. Phelan, A.R. Rincón, S.H. Rogers, F. Turkelboom, W. Van Reeth, B.T. van Zanten, H.K. Wam and C.-L. Washbourneae (2016) A new valuation school: Integrating diverse values of nature in resource and land use decisions. Ecosystem Services 22 (part B) pp. 213-220

Kaltoft, P. (1999) Values about Nature in Organic Farming Practices and Knowledge. Sociologia Ruralis 39 (1) pp. 39-53

Kardol, P., H.L. Throop, J. Adkins and M.-A. de Graaff (2016) A hierarchical framework for studying the role of biodiversity in soil food web processes and ecosystem services. Soil Biology and Biochemistry 102 pp. 33-36

Kelemen, E., G. Nguyen, T. Gomiero, E. Kovács, J.-P. Choisis, N. Choisis, M.G. Paoletti, L. Podmaniczky, J. Ryschawy, J.-P. Sarthou, F. Herzog, P. Dennis and K. Balázs (2013) Farmers' perceptions of biodiversity: Lessons from a discourse-based deliberative valuation study. Land Use Policy 35 pp. 318-328

de Krom, M.P.M.M. (2017) Farmer participation in agri-environmental schemes: Regionalisation and the role of bridging social capital. Land Use Policy 60 pp. 352-361

Krueger, R.A. and M.A. Casey (2009) Focus groups: a practical guide for applied research (Los Angeles, CA: SAGE)

Larrère, C. (2010) Les éthiques environnementales. Natures Sciences Sociétés 18 (4) pp. 405-413

Lastra-Bravo, X.B., C. Hubbard, G. Garrod and A. Tolón-Becerra (2015) What drives farmers' participation in EU agri-environmental schemes?: Results from a qualitative meta-analysis. Environmental Science \& Policy 54 pp. 1-9 
Létourneau, A. (2010) Pour une éthique de l'environnement inspirée par le pragmatisme : l'exemple du développement durable. VertigO 10(1) pp. 1-17

Ludwig, M., P. Wilmes and S. Schrader (2018) Measuring soil sustainability via soil resilience. Science of The Total Environment 626 pp. 1484-1493

Maris, V. (2015) Le capital naturel, une image réduite des valeurs de la nature et des politiques environnementales. Pp. 31-38, in L. Monnoyer-Smith dir., Nature et richesse des nations. La Revue du CGDD (Paris: Commissariat Général au Développement Durable)

Maris, V. and J.-P. Revéret (2009) Les limites de l'évaluation économique de la biodiversité. Les ateliers de l'éthique 4 (1) pp. 52-66

McIntosh, R.P. (1985) The background of ecology: Concept and theory (Cambridge, UK: Cambridge University Press)

McShane, K. (2009) Environmental Ethics: An Overview. Philosophy Compass 4 (3) pp. 407-420

Milestad, R. and S. Hadatsch (2003) Organic Farming and Social-Ecological Resilience the Alpine Valleys of Sölktäler, Austria. Conservation Ecology 8 (1) 3

Minteer, B.A. (2005) Environmental Philosophy and the Public Interest: A Pragmatic Reconciliation. Environmental Values 14 (1) pp. 37-60

Mitchell, E.T. (1945) Dewey's Theory of Valuation. Ethics 55 (4) pp. 287-297

Oldeman, L.R. (1992) Global Extent of Soil Degradation. ISRIC Bi-Annual Report 1991-1992. (Wageningen: ISRIC)

Palmer, C., K. McShane and R. Sandler (2014) Environmental Ethics. Annual Review of Environment and Resources 39 pp. 419-442

Parker, K. A. (1996) Pragmatism and Environmental Thought. Pp 21-37 in A. Light A. and E. Katz eds., Environmental pragmatism (London, UK ; New York, NY: Routledge)

Parker, A. and J. Tritter (2006) Focus group method and methodology: current practice and recent debate. International Journal of Research \& Method in Education 29 (1) pp. 23-37

Pascual, U., M. Termansen, K. Hedlund, L. Brussaard, J.H. Faber, S. Foudi, P. Lemanceau and S.L. Jørgensen (2015) On the value of soil biodiversity and ecosystem services. Ecosystem Services 15 pp. $11-18$

Pauli, N., L.K. Abbott, S. Negrete-Yankelevich and P. Andrés (2016) Farmers' knowledge and use of soil fauna in agriculture: a worldwide review. Ecology and Society 21 (3) n` 19

Plaas E., F. Meyer-Wolfarth, M. Banse, J. Bengtsson, H. Bergmann, J. Faber, M. Potthoff, T. Runge, S. Schrader and A. Taylor (2019) Towards valuation of biodiversity in agricultural soils: A case for earthworms. Ecological economics 159 pp. 291-300

Posthumus, H., L. K. Deeks, I. Fenn and R. J. Rickson (2011) Soil conservation in two English catchments: Linking soil management with policies. Land Degradation \& Development 22 (1) pp. $97-110$

Powlson, D.S., P.J. Gregory, W.R. Whalley, J.N. Quinton, D.W. Hopkins, A.P. Whitmore, P.R. Hirsch and K.W.T. Goulding (2011) Soil management in relation to sustainable agriculture and ecosystem services. Food Policy 36 (Supp. 1) pp. S72-S87 
Prager, K. and M. Curfs (2016) Using mental models to understand soil management. Soil Use and Management 32 pp. 36-44

Prager, K. and H. Posthumus (2010) Socio-economic factors influencing farmers' adoption of soil conservation practices in Europe. Pp. 203-223 in T. L. Napier ed., Human Dimensions of Soils and Water Conservation: A Global Perspective (New York, NY: Nova Science Publishers, Inc.)

Rabiee, F. (2004) Focus-group interview and data analysis. Proceedings of the Nutrition Society 63 pp. $655-660$

Renault, M. (2012) Dire ce à quoi nous tenons et en prendre soin-John Dewey, La formation des valeurs, Note critique. Revue Française de Socio-Économie 9 (1) pp. 247-253

Renault, M. (2016) Une approche transactionnelle des démarches d'élaboration d'indicateurs sociétaux. La méthode du Conseil de l'Europe. Innovations 49 pp. 203-225

Renault, M. (2017) Compter le gratuit, un enjeu moral? Un essai sur l'équivalence. Entreprise \& Société 1 (1) pp. 97-126

Riley, M. (2006) Reconsidering conceptualisations of farm conservation activity: The case of conserving hay meadows. Journal of Rural Studies 22 (3) pp. 337-353

van Riper, C.J., A.C. Landon, S. Kidd, P. Bitterman, L.A. Fitzgerald, E.F. Granek, S. Ibarra, D. Iwaniec, C.M. Raymond and D. Toledo (2017) Incorporating Sociocultural Phenomena into EcosystemService Valuation: The Importance of Critical Pluralism. BioScience 67 (3) pp. 233-244

Rivaud, A. and J. Mathé (2011) Les enjeux cognitifs du défi environnemental dans les exploitations agricoles. Économie rurale 323 pp. 21-35

Roesch-McNally, G.E., A.D. Basche, J.G. Arbuckle, J.C. Tyndall, F.E. Miguez, T. Bowman and R. Clay (2018) The trouble with cover crops: Farmers' experiences with overcoming barriers to adoption. Renewable Agriculture and Food Systems 33 pp. 322-333

Rosenthal, S.B. and R.A. Buchholz (1996) How pragmatism is an environmental ethic. Pp 38-49 in A. Light and E. Katz eds., Environmental pragmatism (London, UK ; New York, NY: Routledge)

Salles, J.-M. (2011) Valuing biodiversity and ecosystem services: Why put economic values on Nature? Comptes Rendus Biologies 334 (5-6) pp. 469-482

Saunders, F.P. (2016) Complex Shades of Green: Gradually Changing Notions of the 'Good Farmer' in a Swedish Context: The 'good farmer' in a Swedish context. Sociologia Ruralis 56 (3) pp. 391407

Schneider, F., T. Ledermann, P. Fry and S. Rist (2010) Soil conservation in Swiss agriculture Approaching abstract and symbolic meanings in farmers' life-worlds. Land Use Policy 27 pp. $332-339$

Siebert, R., M. Toogood and A. Knierim (2006) Factors Affecting European Farmers' Participation in Biodiversity Policies. Sociologia Ruralis 46 (4) pp. 318-340

Sutherland, L.-A., R.J.F. Burton, J. Ingram, K. Blackstock, B. Slee and N. Gotts (2012) Triggering change: Towards a conceptualisation of major change processes in farm decision-making. Journal of Environmental Management 104 pp. 142-151 
Thiele-Bruhn, S., J. Bloem, F.T. de Vries, K. Kalbitz and C. Wagg (2012) Linking soil biodiversity and agricultural soil management. Current Opinion in Environmental Sustainability 4(5) pp. 523528

Thompson, P.B. (1995) The Spirit of the Soil (London; New York, NY: Routledge)

Wahlhütter, S., C.R. Vogl and H. Eberhart (2016) Soil as a key criteria in the construction of farmers' identities: The example of farming in the Austrian province of Burgenland. Geoderma 269 pp. $39-53$

Wall, D.H., A.H. Fitter and E.A. Paul (2005) Chapter one. Developing new perspectives from advances in soil biodiversity research. Pp. 3-27 in R. Bardgett, M. Usher and D. Hopkins eds., Biological Diversity and Function in Soils (Cambridge, MA: Cambridge University Press)

Watson, C.A., D. Atkinson, P. Gosling, L.R. Jackson and F.W. Rayns (2002) Managing soil fertility in organic farming systems. Soil Use and Management 18 (S1) pp. 239-247

Weston, A. (1985) Beyond Intrinsic Value: Pragmatism in Environmental Ethics. Environmental Ethics 7 pp. 321-339

Werner, M., E. Wauters, J. Bijttebier, H.-H. Steinmann, G. Ruysschaert and A. Knierim (2017) Farm level implementation of soil conservation measures: farmers' beliefs and intentions. Renewable Agriculture and Food Systems 32 pp. 524-537

Whalen, J.K. and L. Sampedro (2010) Soil ecology and management (Cambridge, MA: CABI)

Wilson, G.A. and K. Hart (2000) Financial Imperative or Conservation Concern? EU Farmers' Motivations for Participation in Voluntary Agri-Environmental Schemes. Environment and Planning A 32 (12) pp. 2161-2185

Yuhas Byers, P. and J.R. Wilcox (1991) Focus Groups: A Qualitative Opportunity for Researchers. The Journal of Business Communication 28 (1) pp. 63-78

van Zeijts, H., A. Gerdien Prins, E. Dammers, M. Vonk, I. Bouwma, H. Farjon and R. Pouwels (2017) European nature in the plural. Finding common ground for a next policy agenda (The Hague: PBL Netherlands Environmental Assessment Agency) 
Table 1. Key information on the Focus Groups realized in each country (AEM: AgriEnvironmental Measures). 


\begin{tabular}{|c|c|c|}
\hline Country & Number of participants & Farmers characteristics \\
\hline $\begin{array}{c}\text { Lower Saxony } \\
\text { Germany }\end{array}$ & 9 & $\begin{array}{c}\text { All men } \\
\text { Born between } 1954 \text { and } 1989 \\
6 \text { with vocational training, } 1 \text { with technical college degree, } 3 \text { with university degree } \\
\text { Conventional farming } \\
2 \text { farmers engaged in protection soil measures }\end{array}$ \\
\hline $\begin{array}{c}\text { Andalusia } \\
\text { Spain }\end{array}$ & 17 & $\begin{array}{c}\text { All men } \\
\text { Born between } 1941 \text { and } 1992 \\
4 \text { with vocational training, } 11 \text { with university degree (one did not complete it) } 3 \\
\text { without degree } \\
\text { Conventional farming; } 2 \text { with organic farming on a part of the farm and } 2 \text { with } \\
\text { integrated production } \\
5 \text { participants engaged in soil protection measures }\end{array}$ \\
\hline $\begin{array}{l}\text { Brittany } \\
\text { France }\end{array}$ & 6 & $\begin{array}{c}1 \text { woman }-5 \text { men } \\
\text { Born between } 1960 \text { and } 1988 \\
2 \text { with a college degree, } 4 \text { with vocational training } \\
\text { Conventional farming } \\
5 \text { engaged in conservation tillage; } 2 \text { engaged in AEM (dealing with global } \\
\text { environmental issues) }\end{array}$ \\
\hline $\begin{array}{c}\text { Transylvania } \\
\text { Romania }\end{array}$ & 10 & $\begin{array}{c}\text { All men } \\
\text { Born between } 1954 \text { and } 1996 \\
5 \text { with university degree, } 1 \text { with technical college degree, } 2 \text { did not specify } \\
\text { Conventional farming; } 2 \text { farms with parts certified in organic farming } \\
3 \text { engaged in soil protection measures but no information whether it is an officially } \\
\text { funded measure or not }\end{array}$ \\
\hline $\begin{array}{l}\text { Uppland } \\
\text { Sweden }\end{array}$ & 8 & $\begin{array}{c}\text { All men } \\
\text { Born between } 1947 \text { and } 1975 \\
3 \text { with university degree, } 5 \text { with vocational training } \\
4 \text { in conventional farming; } 4 \text { in certified organic farming } \\
\text { All engaged in soil protection measures }\end{array}$ \\
\hline
\end{tabular}


Figure 1. Value taxonomy adapted from Arias-Arévalo (2018). Each box corresponds to one value category. Values domains are written in capital letters. There is no subdivision into categories of the intrinsic and instrumental value domain as they represent moral duties towards nature and monetary values, respectively.

Figure 2. Three-steps study design applied in our pan-European soil and soil biota values investigation.

Figure 3. Values related to soil biota (A and B) and to the soil system as a whole (C and D) resulting from the analysis of two Europe-wide datasets: literature from 1996 to 2018 (N=36 documents, A and C) and Focus Groups in 2017/2018 (N=5 sessions, B and D). Each box corresponds to one value category following the plural value typology of Arias-Arévalo et al. (2018, see Fig. 1). Only indicated values are actually found in the dataset. 


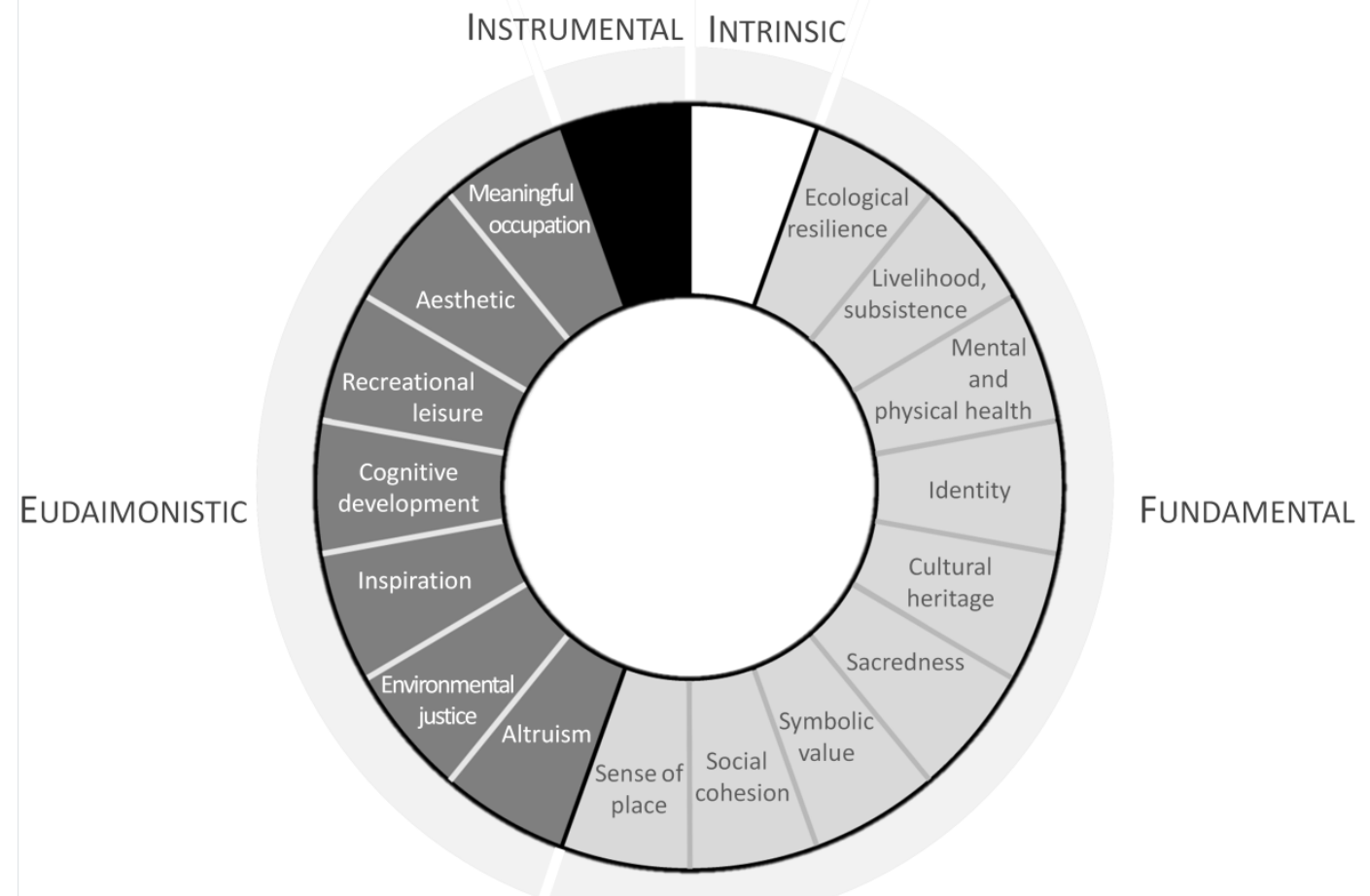

soru_12303_f1.tif 


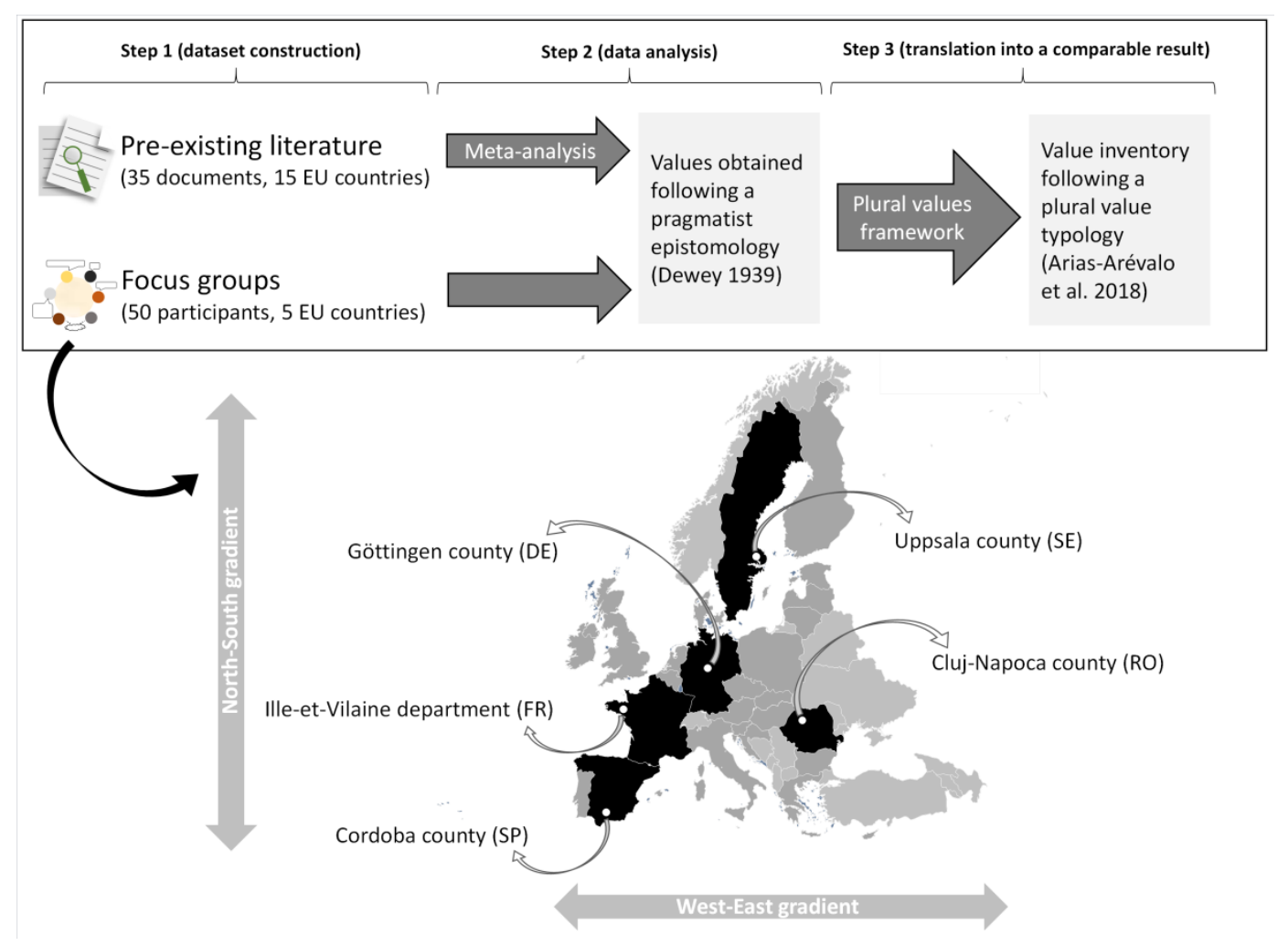

soru_12303_f2.tif 


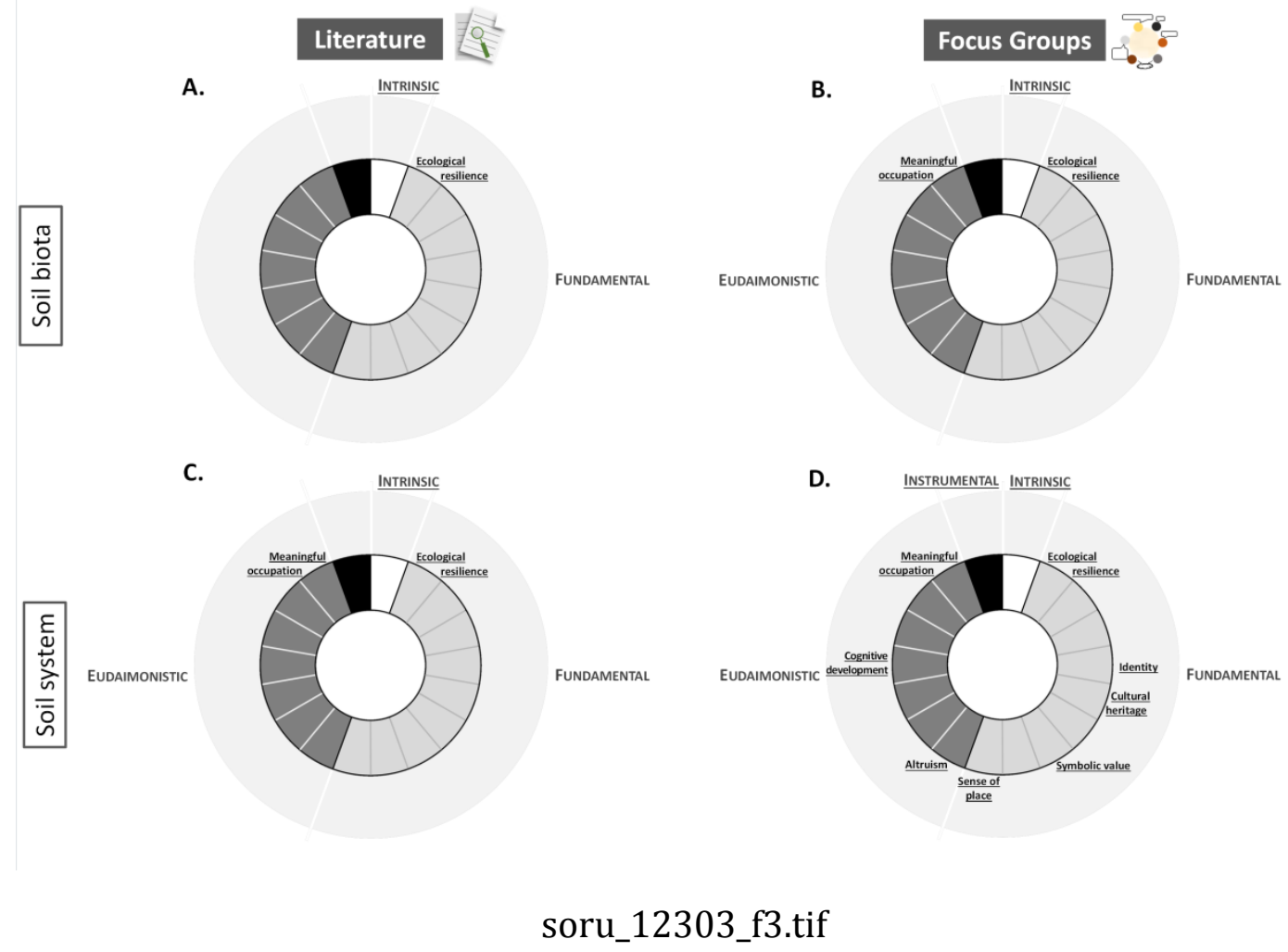

